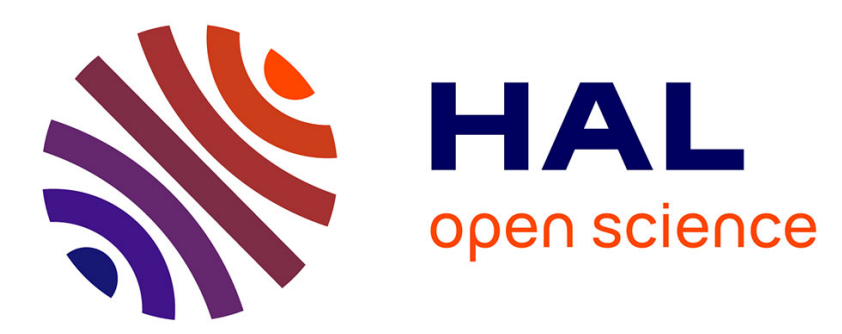

\title{
Enhanced two-photon absorption of ligated silver and gold nanoclusters: theoretical and experimental assessments
}

\author{
Vlasta Bonačić-Koutecký, Rodolphe Antoine
}

\section{- To cite this version:}

Vlasta Bonačić-Koutecký, Rodolphe Antoine. Enhanced two-photon absorption of ligated silver and gold nanoclusters: theoretical and experimental assessments. Nanoscale, 2019, 11 (26), pp.1243612448. 10.1039/C9NR01826C . hal-02980254

\section{HAL Id: hal-02980254 \\ https://hal.science/hal-02980254}

Submitted on 5 Nov 2020

HAL is a multi-disciplinary open access archive for the deposit and dissemination of scientific research documents, whether they are published or not. The documents may come from teaching and research institutions in France or abroad, or from public or private research centers.
L'archive ouverte pluridisciplinaire HAL, est destinée au dépôt et à la diffusion de documents scientifiques de niveau recherche, publiés ou non, émanant des établissements d'enseignement et de recherche français ou étrangers, des laboratoires publics ou privés. 


\title{
Enhanced Two-Photon Absorption of Ligated Silver and Gold Nanoclusters: Theoretical and Experimental
} Assessments.

\begin{abstract}
Vlasta Bonačić-Kouteckýa* and Rodolphe Antoine ${ }^{\mathrm{b} *}$
Ligated silver and gold nanoclusters belonging to a non-scalable size regime with molecular-like discrete electronic states represent an emerging class of extremely interesting optical materials. Nonlinear optical (NLO) characteristics of such quantum clusters have revealed remarkable features. The two-photon absorption (TPA) cross section of ligated noble metal nanoclusters is several orders of magnitude larger than that of commercially-available dyes. Several such case studies on NLO properties of ligated silver and gold nanoclusters have been reported, making them promising candidates for various bio-imaging techniques such as multiphoton-excited fluorescence microscopy. However, the structure-property relationship is of great importance and needs to be properly addressed in order to design new nonlinear optical materials. Using small ligated silver nanoclusters as test systems, we illustrate how theoretical approaches together with experimental findings can contribute to the understanding of structure-property relationships that might ultimately guide nanocluster synthesis.
\end{abstract}

\section{Introduction}

Seeing is fascinating - Since the advent of the first microscopes in the early 17th century, imaging technology has become the "eyes of science", which give biomedical sciences an exquisite sense of vision. As a result, active efforts have been made to improve the resolution, sensitivity, depth of penetration, precision and acquisition time of biological imaging by means of ingenious innovations and advances in imaging targets and instruments. Biological materials such as blood, fat, and skin absorb and disperse any incident light in varying degrees (see Fig. 1a). ${ }^{1}$ Because of this, NIR light (NIR-I window between 700 and $900 \mathrm{~nm}$ ) is usually preferred due to a deeper penetration of biological entities, particularly skin and blood. ${ }^{2}$ Furthermore, imaging in the NIR-II window (between 1000 and $1700 \mathrm{~nm}$ ) allows significantly reduced biological tissue light dispersion and reduced autofluorescence in the background. ${ }^{3,4}$

Understandably, a first strategy consists of developing chromophores with small optical gaps (see Fig. 1b). ${ }^{5-7}$ And recent activities have been focused on the design and development of novel exogenous imaging contrast agents with NIR-I or even NIR-II absorption or emission, including inorganic imaging contrast agents, such as single-walled carbon nanotubes (SWCNTs), 8 metal chalcogenide quantum dots, ${ }^{9}$ wide bandgap semiconducting quantum dots, ${ }^{10}, 11$ rare-earth nanoparticles, ${ }^{12}$ and organic probes in particular organic dyes..$^{13}$ Luminescent ligated noble metal nanoclusters, ${ }^{14}$ especially gold and silver nanoclusters (AuNCs and AgNCs), 15, 16 composed of several up to a few hundreds of Au or Ag atoms and protected by ligands, exhibit quantum confinement effects and moleculelike properties. ${ }^{17,18} \mathrm{Au}$ NCs with tuneable emission from blue to the near-IR (NIR-I) region have been reported in the last several decades, ${ }^{19-33}$ and utilization of those NCs for in vitro cell labelling and in vivo fluorescence imaging applications has been a rich area of research. ${ }^{34-37}$ In recent reports, ligated gold nanoclusters with emission in the NIR-II region have been particularly investigated for in vivo imaging applications. 37,38 A second strategy consists of decreasing the photon energy of the excitation light (to reach the IR windows) by using nonlinear optical processes (see Fig. 1b). ${ }^{39}$ Multiphoton absorption is a nonlinear process based on two or more photons simultaneously absorbed in one event. The most common processes for multiphoton absorption are two and threephoton absorption. Two-photon absorption (2PA or TPA) has found multiple applications in bioimaging mainly because of its high spatial resolution. ${ }^{40-42}$ Furthermore, the wavelengths typically used for TPA excitation are in the NIR-I window (i.e. 700-800 $\mathrm{nm}$ ). In order to reach the NIR-II window, nonlinear processes of a higher order, such as three-photon absorption (3PA) can be employed. ${ }^{43}, 44$ Over the last decade, considerable efforts have been made to develop organic dye molecules,

\footnotetext{
Centre of excellence for Science and Technology-Integration of Mediterranean region (STIM) at the Interdisciplinary Centre for Advanced Sciences and Technology (ICAST), University of Split, Poljička cesta 35, HR-21000 Split, Republic of Croatia and Department of Chemistry, Humboldt Universität zu Berlin, Brook Taylor-Strasse 2, 12489 Berlin, Germany. E-mail: vbk@cms.hu-berlin.de

b. Univ Lyon, Université Claude Bernard Lyon 1, CNRS, Institut Lumière Matière, Lyon, France. E-mail : rodolphe.antoine@univ-lyon1.fr
} 
a)

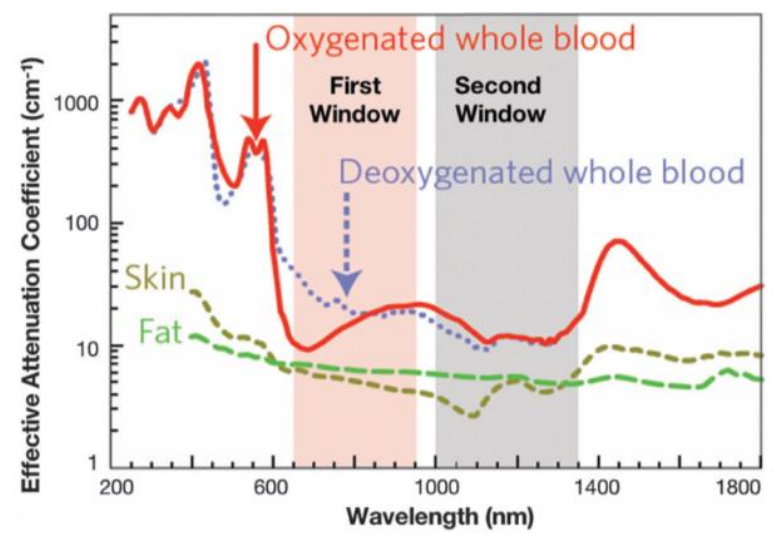

b)
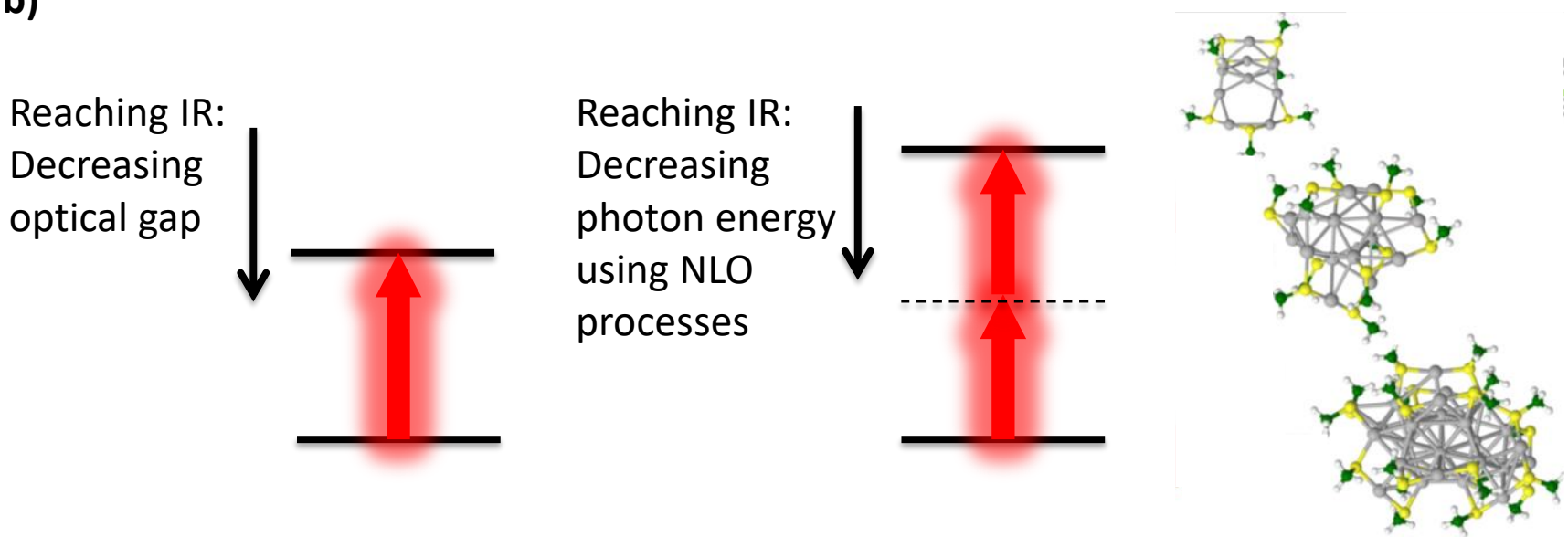

Figure 1: (a) Attenuation of various biological entities, such as oxygenated and deoxygenated whole blood, skin, and fat, over optical wavelengths. Absorption and scattering of these entities are significantly lower in either the first near-infrared window (NIR-I, 700-900 nm, shaded in pink) or the second near-infrared window (NIR-II, 1000-1700 nm, shaded in grey). This figure has been reproduced from ref. 1 with permission from Springer Nature. (b) Strategies for reaching the NIR-I, NIR-II windows, either by developing chromophores with small optical gaps or by using NLO processes with ligated nanoclusters (right-hand panel).

ranging from well-known push-pull dipolar molecular structures, to quadrupoles and complex molecular architectures with large two-photon absorption (TPA) for fluorescence sensing and biological imaging applications. ${ }^{45,46}$

A significant effort has also been made in the past decade for developing organic molecules and semiconductor quantum dots with large two-photon absorption (TPA) ${ }^{47}$ for applications in fluorescence sensing and biological imaging. ${ }^{48}$ Although nonlinear optics has a long history in organic chemistry, the field of NLO in ligated noble metal nanoclusters is relatively new ${ }^{49,50,}$ but fast-growing. ${ }^{51-53}$ Due to molecular-like properties, it is expected that their NLO behaviour, in particular, their nonlinear refraction and absorption (including two-photon absorption, TPA) properties, could be understood in a way analogue to molecular materials. ${ }^{52,54,55}$ In this feature article, we consider the current status of these investigations, with an emphasis on the joint work performed in our two groups. The present feature article presents an elementary description of nonlinear optics focused on two-photon absorption. Current state-of-theart quantum chemistry approaches will be described and the results illustrated by several practical examples that show how ligated gold and silver nanoclusters are interesting candidates as a new class of nonlinear optical nanomaterials.

\section{Theoretical Approaches}

\subsection{Fundamental principles.}

Two-photon absorption (TPA) is the third order, $\chi^{(3)}$, nonlinear optical process whereby, for frequency degenerate TPA, two photons are simultaneously absorbed to raise a system into an excited state of energy equal to that of the sum of the two photons. In this article, we focus on degenerate TPA, which corresponds to two photons of equal energy. The propagation of incident light I, through a sample of thickness $z$ with one- and two-photon absorptions is written as:

$$
\frac{d I}{d z}=-\alpha_{1} I-\alpha_{2} I^{2}(t)-\cdots
$$

where $\alpha_{1}$ and $\alpha_{2}$ are the one- and two-photon absorption coefficients. Higher order nonlinear absorptions are not discussed here. For a given frequency, $\omega$, degenerate TPA is proportional to the imaginary part of third-order susceptibility tensor $\chi^{(3)}$, expressed in SI units as 56 


$$
\alpha_{2}(\omega)=\frac{3 \omega}{2 n^{2} c^{2} \varepsilon_{0}} \operatorname{Im}\left[\chi_{I J}^{(3)}(-\omega ; \omega,-\omega, \omega)\right]
$$

where $n$ is the refractive index and $c$ is the speed of light. To characterize the TPA of individual molecules, one can define the TPA cross-section, $\sigma_{T P A}(\omega)$, which is given in units of $1 \times 10^{50}$ $\mathrm{cm}^{4}$ sphoton $^{-1}$ molecule ${ }^{-1}$. This unit is called "Göppert-Mayer" or "GM" in honour of the author Maria Göppert-Mayer, who developed the theory of two-photon absorption in the 1930 s. $^{57}$ $\sigma_{T P A}(\omega)$ for an individual molecule can be expressed in SI units by:

$$
\sigma_{T P A}(\omega)=\frac{\alpha_{2}(\omega) \hbar \omega}{N}
$$

where $N$ is the number of molecules per unit volume. Below, we will discuss the quantum mechanical approach advanced and used in our theoretical group to model TPA in nanoclusters providing a comprehensive picture of the physics involved in the interaction.

\subsection{Quantum chemical approach}

Two different approaches can be used to evaluate the nonlinear response of molecular systems: the analytical response theory and sum-over-states (SOS) methods, both based on the perturbation theory.

The two-photon cross section for excitation from the ground state $|0\rangle$ to the final state $|f\rangle$ corresponding to experimental measurements is defined as: ${ }^{53}$

$$
\delta_{T P A}=\frac{(2 \pi e)^{4} \omega_{\nu} \omega_{\mu}}{c^{2}} g\left(\omega_{v}+\omega_{\mu}\right)\left|T^{\omega_{\nu} \omega_{\mu}, f}\right|^{2}
$$

where $g\left(\omega_{v}+\omega_{\mu}\right)$ is a normalized line-shaped function and

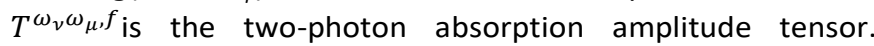
Experimental measurement produces an average TPA crosssection, which can be evaluated by averaging the two-photon transition amplitude tensor $\left|T^{\omega_{\nu} \omega_{\mu}, f}\right|^{2}$ over all orientations. Cartesian components $T_{a b}^{2 \omega, f}$ between the ground state $|0\rangle$ and the excited state $|f\rangle$ are defined as:

$$
T_{a b}^{2 \omega, f}=\sum_{k>0}\left[\frac{\left\langle 0\left|\hat{\mu}_{a}\right| k\right\rangle\left\langle k\left|\hat{\mu}_{b}\right| f\right\rangle}{\omega_{k}-\omega_{f} / 2}+\frac{\left\langle 0\left|\hat{\mu}_{b}\right| k\right\rangle\left\langle k\left|\hat{\mu}_{a}\right| f\right\rangle}{\omega_{k}-\omega_{f} / 2}\right](a, b=x, y, z)
$$

where the frequency of incoming radiation is equal to half of this excitation energy from the ground state $|0\rangle$ to the excited state $|f\rangle$, with $\omega_{k}=\omega_{f} / 2$. Quantities $\mu_{a}$ and $\mu_{b}$ are the Cartesian components of the dipole moments operator $\hat{\mu}$ and $\omega_{k}$ and $\omega_{f}$ are the frequencies of the excitation from $|0\rangle$ to $|k\rangle$ and $|f\rangle$, respectively.

The application of Eq. 5 has limitations because it requires both summations over excited states of the system and computation of matrix elements of dipole moment operator $\hat{\mu}$ between excited states. In order to simplify the procedure, the "few states model", in which dominating terms are considered, became attractive, but calculations nevertheless involve determining transition dipole moments within adequate quantum chemical methods.

A more rigorous way of evaluating TPA transition amplitudes tensor $T^{2 \omega, f}$ is to use the response theory in which a set of coupled equations have to be solved instead of summation over excited states. In this way, necessary information about excited states can be determined by time evaluation of wave function or electron density. Especially in the latter case, the calculation of TPA transition amplitude tensors can be determined for larger molecules and systems and has been implemented in a number of quantum chemical packages.

Environmental effects such as the influence of solvent on nonlinear properties with the polarizable continuum model have also been included in the response theory. For instance, a set of prototypical two-photon chromophores (i.e. pure $\pi$ system, and its substituted homologs obtained employing donor and acceptor groups) have been selected to probe solvent effects. The results show a significant solvent dependence of the TPA cross-section and an unusual trend when passing from cyclohexane to water. ${ }^{58}$

The single residue of the quadratic response function can be rewritten as:

$$
\lim _{\omega_{C} \rightarrow \omega_{f}}\left(\omega_{C}-\omega_{f}\right)\left\langle\left\langle\hat{\mu}_{a} ; \hat{\mu}_{b}, \hat{\mu}_{c}\right\rangle{\frac{\omega_{f}}{2}, \omega_{C}}=-T_{a b}^{2 \omega, f}\left\langle f\left|\hat{\mu}_{C}\right| 0\right\rangle\right.
$$

where $\hat{\mu}_{a} ; \hat{\mu}_{b}, \hat{\mu}_{c}$ are Cartesian components of the dipole moment operator. The right-hand side of Eq. 6 corresponds to the product of a Cartesian tensor element and one-photon absorption Cartesian vector element $\left\langle f\left|\hat{\mu}_{C}\right| 0\right\rangle$. Therefore it can be used to obtain $T_{a b}^{2 \omega, f}$ from the single residue of the quadratic response function. ${ }^{59}$ Using spectral representation, it can be shown that $T_{a b}^{2 \omega, f}$ determined from Eq. 6 is equivalent to the TPA amplitude tensor from Eq. 4, and therefore connects theoretical and experimental observables.

In order to obtain the TPA amplitude tensor, we need to solve a set of response equations which determine the single residue of $\left\langle\left\langle\hat{\mu}_{a} ; \hat{\mu}_{b}, \hat{\mu}_{c}\right\rangle\right\rangle \omega_{f} \omega_{c}$. For this purpose, the description of the quadratic response equations for evaluation of TPA tensors together with the numerical procedures for their solution, are implemented in different quantum chemistry packages. A quadratic response-DFT approach is the most frequently used approach.

To prevent TPA cross-sections from blowing up close to the onephoton resonances, the SOS approach with the damping factor $\Gamma$ can be used, which requires an explicit calculation of all transition dipole moments between excited states as well as between excited states and the ground state:

$\left|T_{f 0}\right|^{2} \sim \sum_{j}^{N} \sum_{k}^{N}\left[\frac{(\langle k|\mu| 0\rangle \cdot\langle f|\mu| k\rangle)(\langle j|\mu| 0\rangle \cdot\langle f|\mu| j\rangle)}{\left[\left(\omega_{k}-\omega\right)\left(\omega_{j}-\omega\right)+\Gamma^{2}\right]}+\right.$ $\left.\frac{(\langle k|\mu| 0\rangle \cdot\langle j|\mu| 0\rangle)(\langle f|\mu| k\rangle \cdot\langle f|\mu| j\rangle)}{\left[\left(\omega_{k}-\omega\right)\left(\omega_{j}-\omega\right)+\Gamma^{2}\right]}+\frac{(\langle k|\mu| 0\rangle \cdot\langle f|\mu| j\rangle)(\langle f|\mu| k\rangle \cdot\langle j|\mu| 0\rangle)}{\left[\left(\omega_{k}-\omega\right)\left(\omega_{j}-\omega\right)+\Gamma^{2}\right]}\right]$

(7) 
Equation (7) is an orientation-averaged expression for the twophoton transition amplitude tensor and is valid only for the degenerate case (i.e. both photons have the same energy $E_{\lambda}$ ) and for linearly polarised photons with parallel polarisation. ${ }^{58}$ Concerning the theoretical results presented in this feature article, the SOS approach (Equation (7)) was adapted and implemented within the DALTON programme 60,61 in the framework of the double residue (DR) approach. Therefore, TPA cross-sections were adequately corrected by damping factor $\Gamma$ with the inclusion of the necessary manifold of states, usually 20-30 excited states. In this manner, a 'few states' model was avoided in which only the dominating terms in the TPA transition amplitude tensor are included. ${ }^{62}$ The truncation of the SOS from e.g. 20 to 15 states on the values of cross sections was tested and no influence has been found.

\subsection{Qualitative assessment of TPA cross-sections.}

From a computational point of view, since a usually large number of excited states has to be calculated within a timedependent density functional theory, the accuracy of the results will depend on limitations of DFT approach such as the choice of functionals and inclusion of only single excitations. Therefore, the calculated nonlinear properties such as TPA cross-sections should be considered to be more of a qualitative nature. However, they should provide the basis for designing systems with large TPA cross-sections stimulating experimental verification.

Day and co-workers did extensive work on calculating twophoton absorption spectra of ligated gold ${ }^{62}$ and silver nanoclusters ${ }^{63}, 64$ using TDDFT. ${ }^{65}$ They investigated on the example of $\mathrm{Ag}_{15}(\mathrm{SCH} 3)_{11}$ the influence of different functionals on geometry as well as TPA spectra and found that structural properties are considerably less sensitive than two-photon cross-sections on the choice of functional ${ }^{63}$. A similar conclusion can be drawn for the TPA spectra of $\mathrm{Au}_{25}(\mathrm{SH})_{18}{ }^{-}$with different functionals and different basis sets. ${ }^{62}$ The damping factor used in equation 7 (to prevent TPA cross sections from blowing up close to one-photon resonance) may also lead to strong variation in TPA band intensities. While this factor generally has a negligible effect on the TPA cross-section for organic dyes, the higher density of states in the metal nanoclusters makes nearresonance conditions more likely, and this damping factor may influence TPA enhancements quantitatively (see Fig. 1b in ref. ${ }^{55}$ ), which, in the end, may produce large unphysical TPA cross-sections at double-resonances. Note, in the frame of the damped response theory, that the two-photon transition moments remain finite and may better describe the doubleresonance effect. ${ }^{66}$ However, conceptual conclusions can be drawn using the theoretical investigations on TPA crosssections.

\subsection{Qualitative design of TPA cross-sections.}

Based on the theoretical description of TPA cross-sections (see Equation 6), it is evident that two factors contribute to enhancing cross-sections, entering as the numerator and denominator in a two-photon absorption amplitude tensor: (i) large dipole transition moments between ground and excited states, as well as among excited states, and (ii) resonance between states involved in the OPA and TPA processes (doubleresonance effects). In order to achieve the required conditions, in particularly large transition dipole moments, the structural, electronic properties, charge and composition of the nanoclusters has to be tuned accordingly. Note also that accurate prediction of OPA is important for predicting the spectral range for TPA enhancement due to determined values of excitation energies (see section 4).

\section{Experimental Methodology}

In this section, we will focus on the experimental methodologies developed to extract nonlinear absorption and nonlinear refraction processes. Z-scan and two-photon upconverted fluorescence techniques are among the most used experimental methods for determining optical nonlinearities. The experimental TPA cross-sections we develop in our group have been derived by the P-scan technique. These three techniques are summarized in Figure 2.

The Z-scan method (fig. 2a) measures the nonlinear transmittance of a sample. ${ }^{67}$ In the open-aperture configuration, transmittance is measured as a function of intensity, as the sample is scanned (Z-position) through the focal plane of a tightly focused Gaussian laser beam. The change in transmission as a function of the beam waist gives access to nonlinear absorption. Adding an aperture after the sample (close-aperture configuration), the nonlinear phase change can be detected by changes in transmittance through the aperture onto the detector (related to the nonlinear refraction). ${ }^{68,69}$ The main advantage of the Z-scan technique is that this method enables direct nonlinearity measurements to be made without using reference samples and it therefore minimizes experimental errors. However, the Gaussian laser beams need to be fully characterized (spatially and temporally) along with a perfect alignment at each wavelength, which makes the technique time-consuming. 
a)

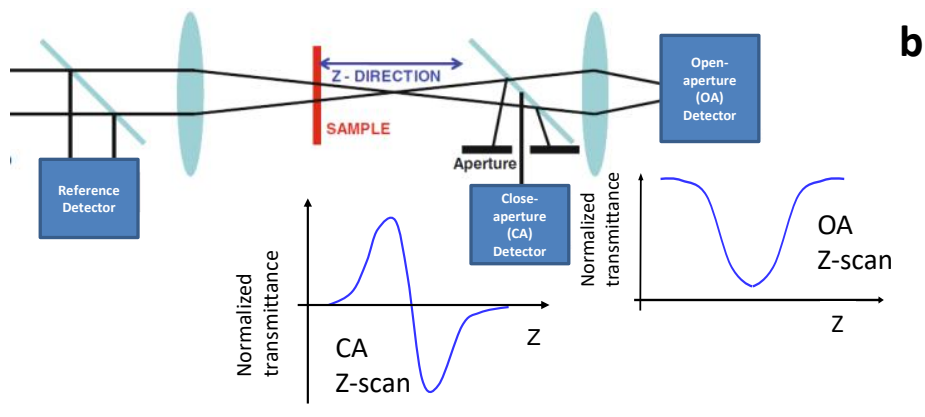

$\lambda / 2$

b)

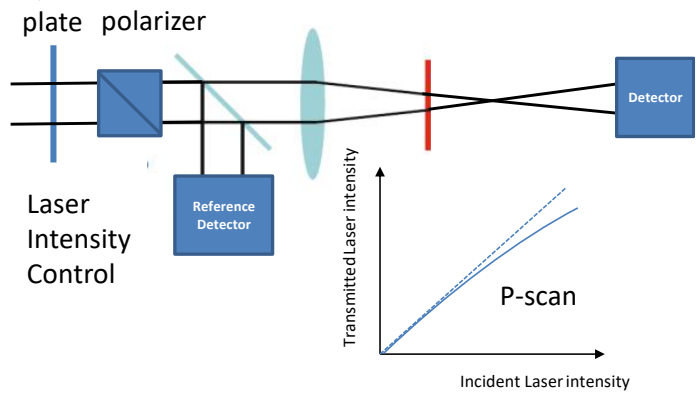

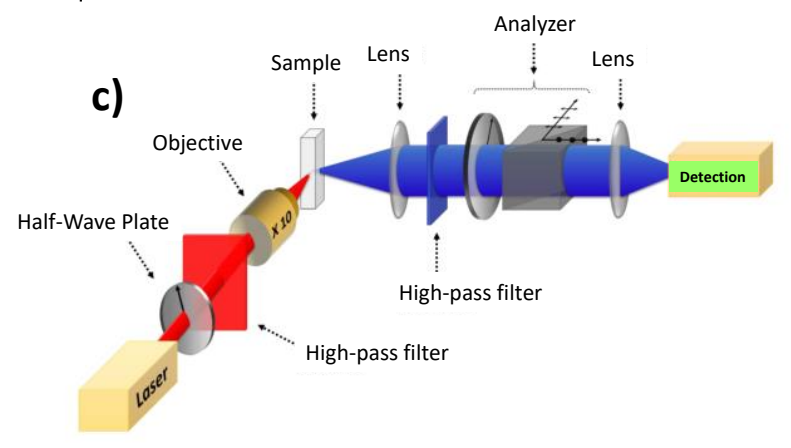

Figure 2: Schematic view of a set-up able to measure two-photon absorption cross-sections. (a) Classical z-scan set-up geometry. Open and Close aperture z-scan principles, along with corresponding transmittance as a function of distance Z. (b) P-scan set-up geometry and (c) Two-photon excited fluorescence set-up geometry.

We have developed an alternative technique named P-scan (or Power-scan) as a simple and rapid technique for measuring nonlinear absorption of samples (see Fig. 2 b). In this method, the incident power is directly varied and the induced changes in the sample transmission are measured. ${ }^{70}$ For small nonlinear effects, the absorption coefficients' expansion can be reduced to Eq. (8). The transmission factor $T$ of the sample can then be expressed as a function of the laser pulse power $P_{m}$ :

$$
T\left(P_{m}\right) \approx T(0)-T(0) \alpha_{2} L_{e f f} \frac{(1-R) P_{m}}{\pi \omega_{0}^{2}}
$$

Where the effective length $L_{\text {eff }}$ is used to correct the intensity decrease along the depth of the sample due to linear absorption. $R$ is the sample front interface reflection coefficient and $\omega_{0}$ is the beam waist. It is possible to extract $\alpha_{2}$ from the slope of the transmitted intensity vs. $P_{m}$ dependence.

The $P$-scan configuration offers at least two advantages over the traditional Z-scan measurements, namely, it is less timeconsuming and is less sensitive to geometry issues (parallelism, reflections, dust, etc.). For metal nanoclusters, we reported some femtosecond P-scan measurements using a mode-locked femtosecond Ti:sapphire laser. ${ }^{54,55,71-75}$

The two-photon excited fluorescence (TPEF) technique (Fig. 2c) measures the fluorescence signal induced by two-photon absorption and derives the TPEF action cross section by comparison with a reference compound or with the one-photon excited fluorescence of the same compound. ${ }^{76,77}$ Note that the TPA cross sections are calculated using one-photon quantum yields (1PQY). ${ }^{78}$ While this assumption is commonly accepted in the photochemistry community, it might be erroneous for ligated gold and silver nanoclusters, where one-photon quantum yields are usually different from their two-photon quantum yields. ${ }^{54,74,75}$ The two-photon excited femtosecond timeresolved fluorescence up-conversion was proposed by Goodson et al. ${ }^{49,79}$ for ensuring accurate measurement of the TPA cross-section of gold nanoclusters.

\section{4 "Ligand-core" NLO-phores}

As already mentioned, due to the extreme sensitivity to excitation energies, an accurate prediction of OPA is an important prerequisite for making assessments on the spectral range for TPA enhancement. As an illustration, the experimental and theoretical OPA spectra of $\mathrm{Ag}_{31}(\mathrm{SG})_{19}$ are displayed in fig. 3 a). The absorption spectrum presents an intense characteristic peak centred at about $490 \mathrm{~nm}$ with an absorption onset close to $700 \mathrm{~nm}$. This band is well reproduced both in intensity and wavelength position by the TDDFT linear absorption spectra. Here, theoretical modelling of glutathione (SG) is simplified by using the $\mathrm{SCH}_{3}$ group. In the $\mathrm{Ag}_{31}\left(\mathrm{SCH}_{3}\right)_{19}$ structure, the core is formed by 21 silver atoms and contains 12 delocalised electrons. The TDDFT linear absorption spectrum for $\mathrm{Ag}_{31}\left(\mathrm{SCH}_{3}\right)_{19}$ shows a large characteristic peak located at 500 $\mathrm{nm}$. This band arises due to core-to-core excitation within the metal core (from D-cluster-core orbital to F-cluster-core orbital), as shown on the right-hand side of Fig. 3 a). ${ }^{54,80,81}$ The 

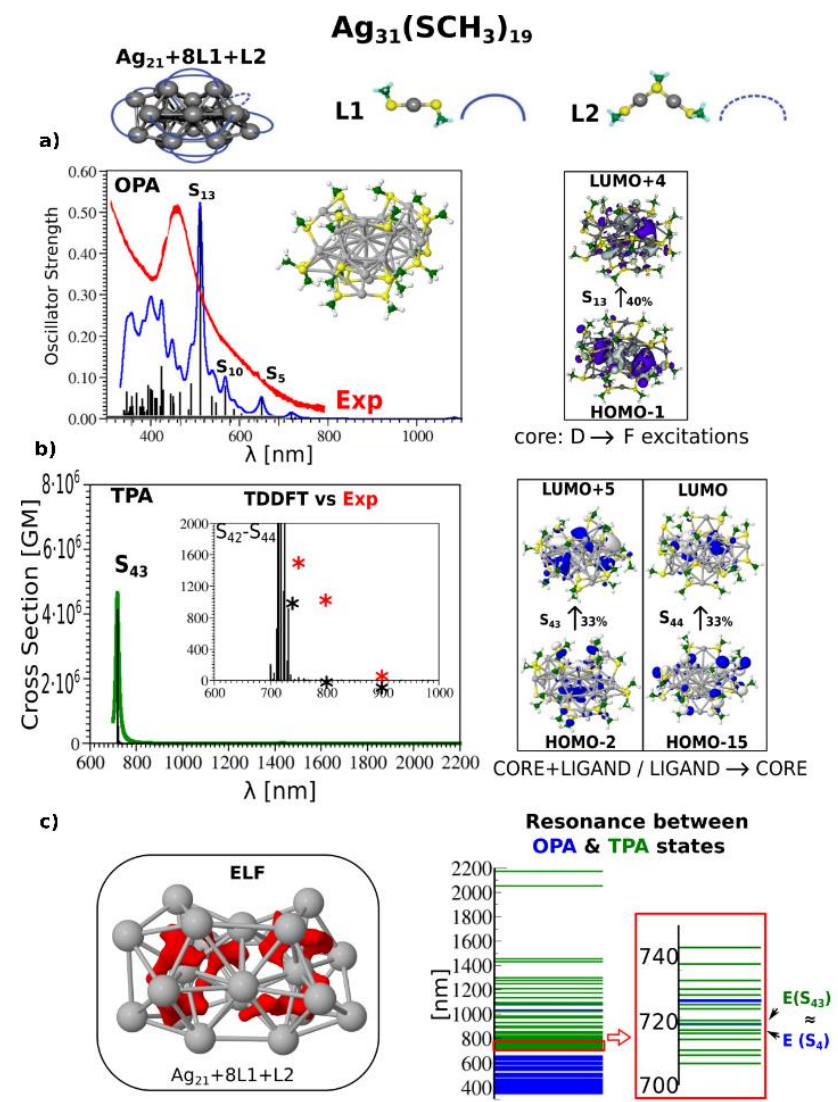

two-photon absorption (TPA) spectrum for the optimized structure of $\mathrm{Ag}_{31}\left(\mathrm{SCH}_{3}\right)_{19}$ obtained with the quadratic response

Figure 3: a) Comparison of experimental and TDDFT OPA spectra of $\mathrm{Ag}_{31}\left(\mathrm{SCH}_{3}\right)_{19}$ nanoclusters for the lowest energy structure. (b) TDDFT TPA spectrum. Red asterisks label experimental values, while the black ones label theoretical values. Leading excitations responsible for OPA and TPA cross-sections illustrating the participation of the ligands and the core are also shown. (c) Structure of the cluster together with electron localization function (ELF) representing delocalized electrons within the core plotted for the isovalue 0.20 (left). Illustration of the resonance between OPA and TPA states (right).

QR- DFT method and the sum-over-states (SOS) approach for each one-photon transition is presented in Fig. 3b. Significant TPA enhancement occurs when the excitation energy of an OPA state is close to half that of a TPA state (double-resonance effect). This is well illustrated on the right-hand side of Fig. 3c, with the resonance of OPA and TPA states close to the 700-740 $\mathrm{nm}$ range. In fact, the fourth excited state at $718 \mathrm{~nm}$ is in resonance with several states close to $360 \mathrm{~nm}$, resulting in an extremely large calculated TPA of over $10^{6} \mathrm{GM}$ (see Fig. 3b). In addition, large transition dipole moments have been obtained and are due to ligand-to-core or inversely core-to-ligand excitations. They are induced by a non-uniform electronic distribution in the metal core as shown on the left-hand side of the Fig. 3c). 54,82

Our thorough investigations on ligand-protected silver and gold clusters have shown that the structure of the metal atom core, its charge, and its symmetry, dramatically influence NLO crosssections. Moreover, the core stabilizing ligands play a key role in NLO efficiencies, particularly due to ligand-to-core or inversely core-to-ligand excitations. Therefore, we call this new class of NLO materials: "Ligand-Core" NLO-phores. ${ }^{51,52,54}$

As illustrated with ligated silver nanoclusters, the interplay between the resonance of OPA and TPA states and large transition dipole moments is essential for enhanced TPA crosssections. Large transition dipole moments are induced by a nonuniform electronic distribution in the metal core. As the size of the nanoclusters increases, it is expected that transition dipole moments should continue to increase due to larger core sizes (and thus larger core-to-ligand distances) and/or non-uniform electronic distribution in the metal core. The ground state charge of nanoclusters can be tuned (as demonstrated for Au25 $5^{q}$ clusters with $\left.q=-1,0,+1\right), 83,84$ enabling the impact on NLO properties of charged active sites to be probed. Also, the optical band gap decreases as the size of the nanoclusters increases, ${ }^{18}$ shifting the bands in OPA spectra, and consequently double-resonance effects, towards the NIR spectral region, a feature useful for bio-imaging applications. Finally, by increasing the size of nanoclusters, a transition from "molecular-like" to "metal-like" is expected as recently reported by Pradeep and collaborators where metallicity in silver nanoclusters emerges for core sizes of about 150 atoms. ${ }^{85}$ For such sizes governed by plasmon-like excitations, ligands will have a moderate role. Interesting new NLO behaviours are supposed to occur at this transition from "molecular-like" to "metal-like" behaviours for which surface vs volume contributions will be different. ${ }^{86-89}$

\section{Two-photon absorption and two-photon emission cross-sections of ligated gold and silver nanoclusters}

Since the pioneering work of Goodson and co-workers ${ }^{49}$, who were the first to reveal giant TPA cross-sections for $\mathrm{Au}_{25}(\mathrm{SR})_{18}$ nanoclusters, several works have been reported on the twophoton absorption and/or two-photon excited fluorescence cross-sections, as summarized in Table 1.49, 72, 75, 90-95 In line with these reported results, we can determine certain figures of merit for the NLO properties of gold NCs. First, with the increase in nanocluster size, NLO cross-sections also increase (compare TPA cross sections at $800 \mathrm{~nm}$ for $\mathrm{Au}_{10}, \mathrm{Au}_{15}$, and $\mathrm{Au}_{25}$ with glutathione as a ligand). However, it is often difficult to make a quantitative comparison of the results reported in Table 1, because of the use of different techniques and different TPA quantities. For a given size (i.e. $\mathrm{Au}_{25}$ largely explored), large deviations in TPA cross sections are observed (from $830 \mathrm{GM}$ to $427000 \mathrm{GM}$ at $800 \mathrm{~nm}$ !). This may be partly be explained by the different techniques used. For instance, Liu et al. compared TPA cross sections measured for $1.33 \mathrm{~nm}$ Au NCs protected by 11-mercaptoundecanoic acid with Z-scan and 2PEF methods and obtained values of $8761 \mathrm{GM}$ and $3426 \mathrm{GM}$, respectively. ${ }^{96}$ However, more subtle effects such as the nature of ligands, the structure and charge of the gold core, as well as the solvent might influence TPA cross-sections. Thus, a more rigorous exploration of the ligand effect for example, as we did for the second harmonic response of $\mathrm{Au}_{25} \mathrm{SR}_{18} 73,75$ could offer a better explanation of reported discrepancies. Secondly, we note that 


\begin{tabular}{|c|c|c|c|c|}
\hline references & Nanoclusters & Technique & TPA results & TPEF results \\
\hline $\begin{array}{l}\text { Ramakrishna et al } \\
\text { Ref. } 49\end{array}$ & $\begin{array}{l}\mathrm{Au}_{25} \mathrm{SR}_{18} ; \mathrm{SR} \text { : hexane } \\
\text { thiolate in hexane }\end{array}$ & $\begin{array}{l}\text { one and two-photon excited } \\
\text { femtosecond time-resolved } \\
\text { fluorescence upconversion }\end{array}$ & $(800 \mathrm{~nm}) 427000 \mathrm{GM},(1290 \mathrm{~nm}) 2700 \mathrm{GM}$ & \\
\hline $\begin{array}{l}\text { Philip et al. } \\
\text { Ref. } 94\end{array}$ & $\begin{array}{l}\mathrm{Au}_{25} \mathrm{SR}_{18}, \mathrm{Au}_{38} \mathrm{SR}_{24} \\
\mathrm{Au}_{144} \mathrm{SR} \mathrm{R}_{60} ; \mathrm{SR}: \\
\mathrm{CH}_{2} \mathrm{CH}_{2} \mathrm{Ph} \text { in toluene }\end{array}$ & nanosecond Z-scan & $\begin{array}{l}\text { Two photon absorption coefficient } b(532 \\
\mathrm{nm}): \mathrm{Au}_{25}: 2.0 \times 10^{-10} \mathrm{~m} / \mathrm{W}, \mathrm{Au}_{38}: 3.5 \times 10^{-10} \\
\mathrm{~m} / \mathrm{W}, \mathrm{Au}_{144}: 7.5 \times 10^{-10} \mathrm{~m} / \mathrm{W}\end{array}$ & \\
\hline $\begin{array}{l}\text { Polavarapu et al. } \\
\text { Ref. } 94\end{array}$ & $\begin{array}{l}\mathrm{Au}_{25} \mathrm{SR}_{18} ; \mathrm{SR} \text { : } \\
\text { glutathione in water } \\
\text { (assigment based on } \\
\text { optical spectra) }\end{array}$ & femtosecond Z-scan & $(800 \mathrm{~nm}) 189740 \mathrm{GM}$ & \\
\hline $\begin{array}{l}\text { Oh et al. } \\
\text { Ref. } 92\end{array}$ & $\begin{array}{l}\sim \mathrm{Au}_{102} \mathrm{SR}_{22} ; \mathrm{SR}: \mathrm{TA}-\mathrm{PEG}- \\
\mathrm{NH}_{2} \text { in water }\end{array}$ & $\begin{array}{l}\text { femtosecond } \\
\text { fluorescence excited } \\
\text { fluorescence :, 870-1300 nm }\end{array}$ & $\begin{array}{l}\text { decreasing from } 670 \mathrm{GM} \text { at } 870 \mathrm{~nm} \text {, to } 130 \\
\mathrm{GM} \text { at } 1300 \mathrm{~nm} \text { (assuming TPA cross section } \\
=\mathrm{TPEF} \text { cross section / }{ }^{\mathrm{OPE} Q \mathrm{Q}} \text { ) }\end{array}$ & $\begin{array}{l}\text { decreasing from } 32 \mathrm{GM} \text { at } 870 \\
\mathrm{~nm} \text {, to } 6 \mathrm{GM} \text { at } 1300 \mathrm{~nm}\end{array}$ \\
\hline $\begin{array}{l}\text { Russier-Antoine et al. } \\
\text { Ref. } 75\end{array}$ & $\begin{array}{l}\mathrm{Au}_{15} \mathrm{SR}_{13}, \mathrm{Au}_{25} \mathrm{SR}_{18} ; \mathrm{SR}: \\
\text { glutathione in water }\end{array}$ & $\begin{array}{l}\text { Femtosecond P-scan, } \\
\text { femtosecond fluorescence } \\
\text { excited fluorescence }\end{array}$ & $\mathrm{Au}_{15}(780 \mathrm{~nm}): 65700 \mathrm{GM}$ & $\begin{array}{l}\mathrm{Au}_{15}(780 \mathrm{~nm}): 0.82 \mathrm{GM}, \mathrm{Au}_{25} \\
(780 \mathrm{~nm}): 4.99 \mathrm{GM}\end{array}$ \\
\hline $\begin{array}{l}\text { Hamanaka et al. } \\
\text { Ref. } 91\end{array}$ & $\begin{array}{l}\mathrm{Au}_{25} \mathrm{SR}_{18} ; \mathrm{SR}: 1- \\
\text { dodecanethiol in } \\
\text { toluene }\end{array}$ & $\begin{array}{l}\text { Femtosecond Pump-probe } \\
\text { differential }\end{array}$ & $\operatorname{Imc}(3) / a: A_{25}: 2 \times 10^{-15}$ esu.cm & \\
\hline $\begin{array}{l}\text { Olesiak-Banska et al. } \\
\text { Ref. } 93\end{array}$ & $\begin{array}{l}\mathrm{Au}_{25} \mathrm{SR}_{18} ; \mathrm{SR} \text { :Captopril } \\
\text { in water }\end{array}$ & femtosecond Z-scan & $\begin{array}{l}(550 \mathrm{~nm}) 23800 \mathrm{GM},(800 \mathrm{~nm}) 830 \mathrm{GM} \text { and } \\
(900 \mathrm{~nm}) 1510 \mathrm{GM}\end{array}$ & \\
\hline $\begin{array}{l}\text { Al Kindi et al. } \\
\text { Ref. } 90\end{array}$ & $\begin{array}{l}\left(\mathrm{Au}_{8}\right)_{\mathrm{n}} \mathrm{BSA} ; \mathrm{BSA}: \\
\text { bovine serum albumin }\end{array}$ & $\begin{array}{l}\text { Femtosecond fluorescence } \\
\text { excited fluorescence }\end{array}$ & $\begin{array}{l}(740 \mathrm{~nm}) \mathrm{Au}_{8}: 188 \mathrm{GM}, 2 \mathrm{Au}_{8}: 294 \mathrm{GM}, 3 \mathrm{Au}_{8}: \\
537 \mathrm{GM} \text { (assuming TPA cross section = TPEF } \\
\text { cross section / }{ }^{\text {OPE }} \mathrm{QY} \text { ) }\end{array}$ & $\begin{array}{l}(740 \mathrm{~nm}) \mathrm{Au}_{8}: 2.40 \mathrm{GM}, 2 \mathrm{Au}_{8}: \\
3.42 \mathrm{GM}, 3 \mathrm{Au}_{8}: 5.16 \mathrm{GM}\end{array}$ \\
\hline $\begin{array}{l}\text { Bertorelle et al. } \\
\text { Ref. } 72\end{array}$ & $\begin{array}{l}\mathrm{Au}_{10} \mathrm{SR}_{10}, \mathrm{SR}: \\
\text { glutathione in water }\end{array}$ & $\begin{array}{l}\text { Femtosecond P-scan and } \\
\text { femtosecond fluorescence } \\
\text { excited fluorescence }\end{array}$ & $(800 \mathrm{~nm}) 10 \mathrm{GM}$ & $(800 \mathrm{~nm}) 0.012 \mathrm{GM}$ \\
\hline
\end{tabular}

Table 1: Summary of NLO properties of gold NCs.

protected gold quantum clusters are excellent two-photon absorbers, but poor two-photon excited emitters (compare TPA and TPEF cross-sections in Table 1). However, we must note that some groups have reported both TPA and TPEF cross-sections using the assumption that ${ }^{O P E} Q Y={ }^{T P E} Q Y$. Most of the people working in the photochemistry field generally accept Kasha's rule and Vavilov's rule. ${ }^{97,} 98$ Briefly, in a condensed phase, if fluorescence spectrum and the lifetime by two-photoexcitation are respectively the same as those created by onephoton excitation, fluorescence would originate from thermally equilibrated excited states irrespective of the excitation wavelength. We have shown (by measuring TPA and TPEF crosssections independently) that this assumption is not necessarily true in the NLO regime. We have also investigated two-photon excited fluorescence and two-photon absorption of $\mathrm{Ag}_{29}(\mathrm{DHLA})_{12}$. A giant two-photon absorption cross-section of $\sim$ $510^{4} \mathrm{GM}$ was reported for $\mathrm{Ag}_{29}$ while the corresponding twophoton excited fluorescence cross-section is only $0.5 \mathrm{GM}$. Thus ${ }^{T P E} Q Y=10^{-5}$ while ${ }^{O P E} Q Y=210^{-2}$. We have also observed for the $\mathrm{Ag}_{29}$ interesting behaviour concerning its emission properties following absorption of 1 or 2 photons, as shown in figure 4 . With excitation by one photon at $400 \mathrm{~nm}$ or by two photons at $800 \mathrm{~nm}$, the resulting emission spectrum is either blue or red. Thus, it seems that ligated gold and silver nanoclusters, as well as certain organic molecules, tend to break Kasha's rule and emit at more than one possible wavelength depending on the electronic structure, density of states and the excited state dynamics involved. Note that the photochemistry of nanoclusters is more complex than the de-excitation of $\pi-\pi *$ states of organic molecules, where excitations within the gold core as well as couplings with surface states (through LMCT and LMMCT), singlet to triplet states conversion, are supposed to occur (see Fig. 4). 
Even if ligated gold nanoclusters possess moderate TPEF crosssections in the near-IR range, they were considered to be good candidates for applications in two-photon cellular imaging. Polavarapu et al. ${ }^{95}$ pioneered this field by reporting two-photon excitation fluorescence imaging of SH-SY5Y human neuroblastoma cells incubated with glutathione-protected gold nanoclusters under excitation of femtosecond laser pulses at $800 \mathrm{~nm}$. Water-soluble fluorescent gold nanoclusters for cellular imaging by two-photon excited fluorescence were also reported by Nienhaus and coworkers. ${ }^{36,} 99$ The biological utility
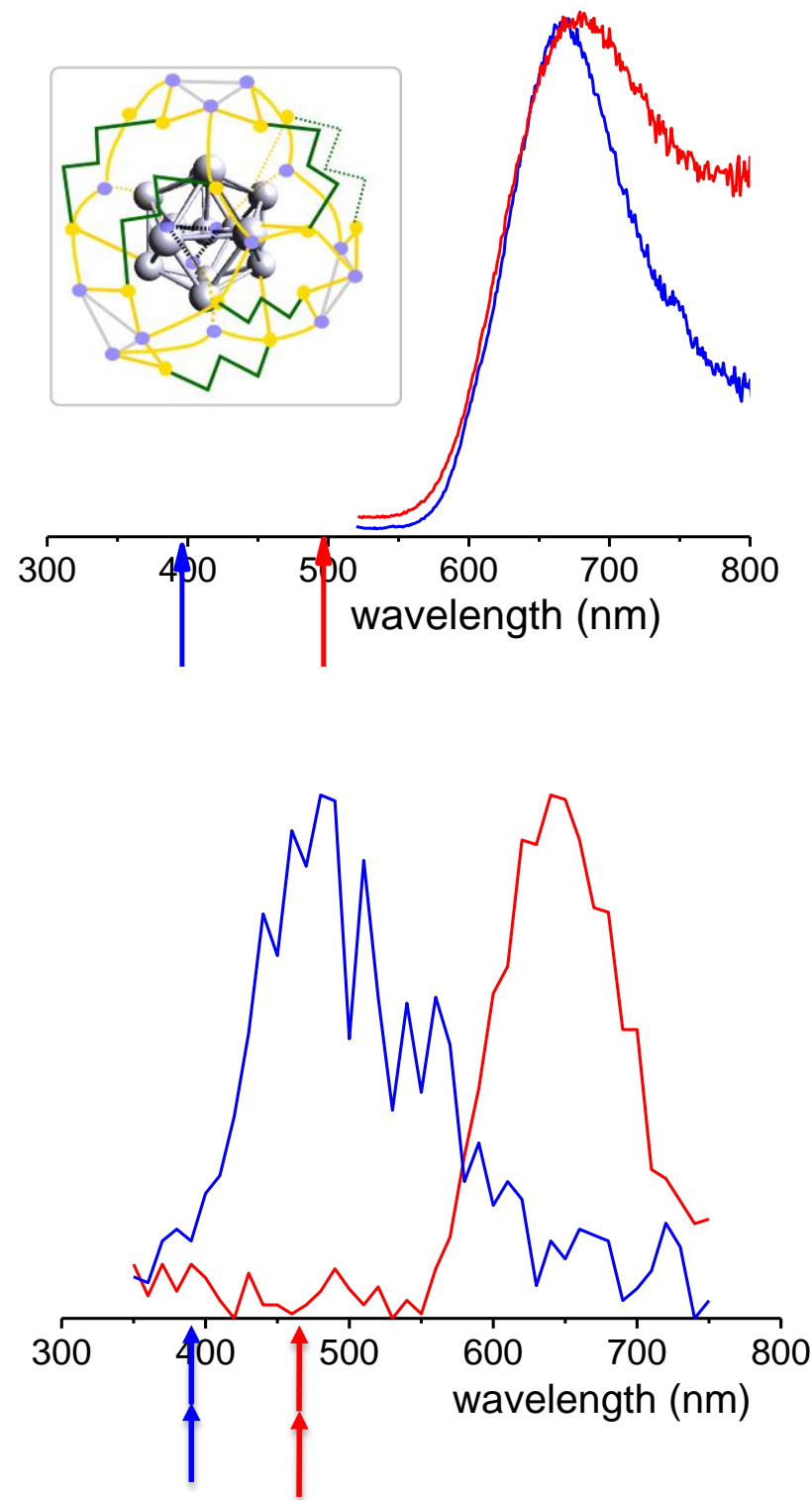

Figure 4: OPEF spectrum (top) and TPEF spectrum (bottom) of the synthesized $\mathrm{Ag}_{29}(\mathrm{DHLA})_{12}$ clusters dispersed in water. The arrows represent the wavelength of excitation by OPE and TPE processes. (inset) Illustrative presentation of DFT optimized structures of $\mathrm{Ag}_{29}(\mathrm{DHLA})_{12}$ showing two different structural classes. The DHLA is represented by $\mathrm{S}-(\mathrm{CH} 2)_{3}-\mathrm{S}$ and carboxylic tail is replaced by one $\mathrm{H}$ atom. On the left hand side: the central silver atom and twelve silver atoms are labelled by grey balls bound to twelve $S$ atoms (yellow balls) forming highly symmetrical subunit. Additional silver atoms involved in staples $\mathrm{S}$-Ag-S are labelled by blue spheres, while green lines denote $3 \mathrm{CH}_{2}$ groups.

of gold nanoclusters was demonstrated by bio-conjugating
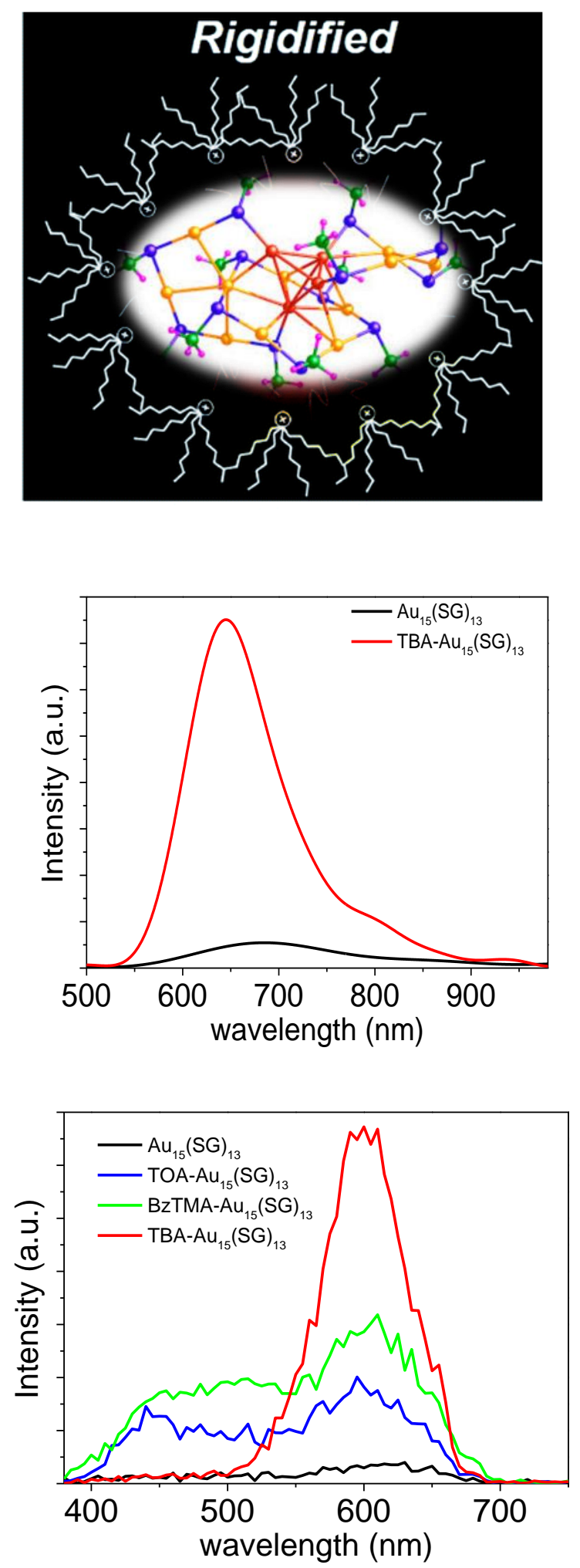

Figure 5: (top) Schematic structure of bulky counterions used to bind to glutathione-protected gold clusters. (middle) One-photon excited fluorescence spectra of $\mathrm{Au}_{15}(\mathrm{SG})_{13}$ in water and TBA-Au${ }_{15}(\mathrm{SG})_{13}$ in methanol. (bottom) Twophoton excited fluorescence spectra at excitation wavelength $780 \mathrm{~nm}$ of $\mathrm{Au}_{15}(\mathrm{SG})_{13}$ in aqueous solution compared to different bulky cations- $\mathrm{Au}_{15}(\mathrm{SG})_{13}$ in methanol. 
them with cell penetrating peptides permitting subsequent endocytic uptake in COS-1 and HeLa cells followed by imaging with multiphoton microscopy. ${ }^{92}$ Also, strategies aiming at protecting gold nanoclusters by protein templates for imaging cells by two-photon excitation in the near IR were successfully reported by Khandelia et al. ${ }^{100,101}$ and Liu et al. ${ }^{102}$

\section{Outlook and Conclusions}

This feature article highlights recent advances in the rapidly growing field of nonlinear optics in ligated gold and silver nanoclusters. We chose to focus this paper on their two-photon absorption properties for which a complementary theoretical and experimental investigation has enabled general rules to be drawn up. The concept of "ligand-core NLO-phore" can be used as a design strategy for enhancing two-photon absorption of small ligated gold and silver nanoclusters. Indeed, such nanoclusters can be viewed as a "multi-shell system" composed by a metallic core, a metal-ligand interface, (through the metalsulphur bonds) and the surface ligand molecules. These shells may communicate either by charge transfer from ligand to metal core (analogy with ligand-to-metal charge transfer (LMCT) or ligand-to metal- metal charge transfer (LMMCT) observed in metal complexes) or through direct bonding or direct donation of delocalized electrons of electron-rich groups of ligands. ${ }^{103}$ Such "communications" between ligands and the metal core are the key ingredients for increasing transition dipole moments leading to enhanced TPA cross-sections. Furthermore, the molecular-like behaviour of such nanoclusters allows for a small optical gap that can reach the near IR range and can push the limit of enhanced TPA cross-sections towards near-infrared biological windows. Even if some preliminary studies have shown that outstanding TPA cross-sections render nanoclusters good candidates for applications in two-photon cellular imaging, there is still a lot of room for making further improvements. Indeed, reported TPEQY for ligated silver and gold nanoclusters are extremely weak $\left(<10^{-4}\right)$, which preclude their use as biphotonic imaging probes. A first strategy for obtaining high quantum yield consists of minimizing the nonradiative relaxation process. Indeed, ligands generally used for protecting nanoclusters are "floppy", enabling significant relaxation of excited states to take place on photon excitation. To enhance quantum yields, ligand shell rigidity is an interesting strategy that would allow for enhanced photon emission when compared to non-radiative relaxation upon photo-excitation. Pyo et al. ${ }^{104}$ have reported OPEF quantum yield $>60 \%$ for glutathione-protected gold nanoclusters by rigidifying the metal-sulphur interface by binding bulky groups. We recently pushed this strategy even further to the nonlinear optical regime. ${ }^{71}$ The strategy uses bulky ammonium counterions which interact with the NC surface by electrostatic interaction to protect it from the environment and also to "rigidify" its surface. The effect is spectacular both on OPEF and TPEF spectra, as shown with $\mathrm{Au}_{15} \mathrm{SG}_{13}$ (see Fig. 5), and the TPEF cross section at $800 \mathrm{~nm}$ in the range of 0.1 to $1 \mathrm{GM}$ can be obtained.
This rigidification effect could be further explored by engineering ligand flexibility (cross-linking, electrostatic interactions,...).

Other recent advances in tailoring one-photon excited fluorescence of nanoclusters have been proposed (and have been summarized in Manzhou Zhu's recent review ${ }^{105}$ ) by (1) engineering the peripheral ligands on the nanocluster surface; 2) modifying the core shape and size or alloying the metal core

\section{One photon excitation}

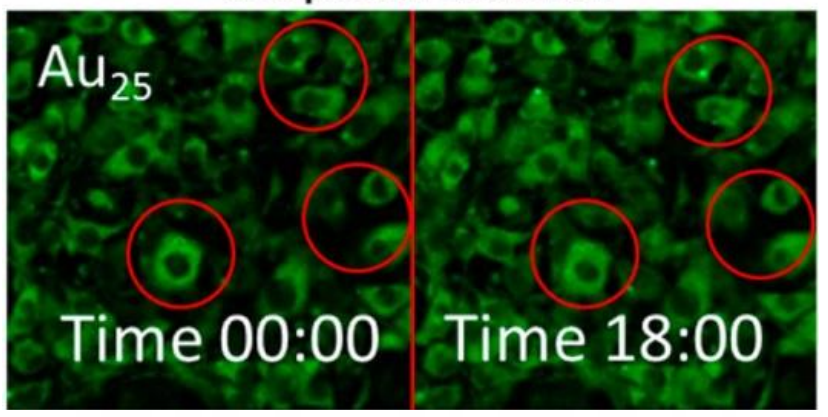

Two photon excitation

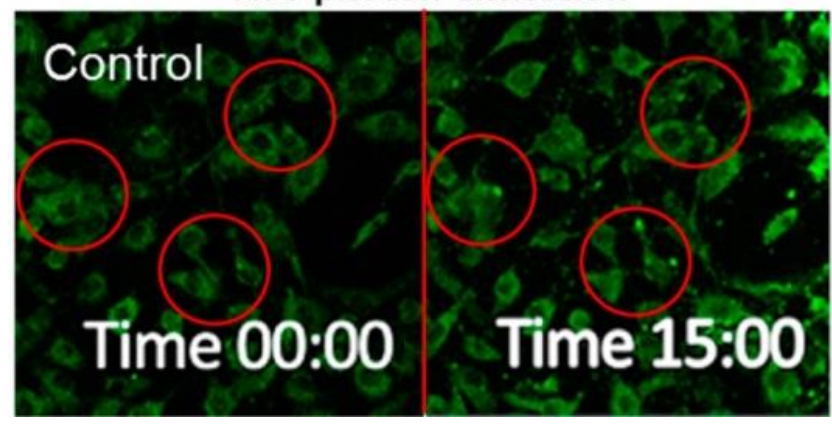

Two photon excitation

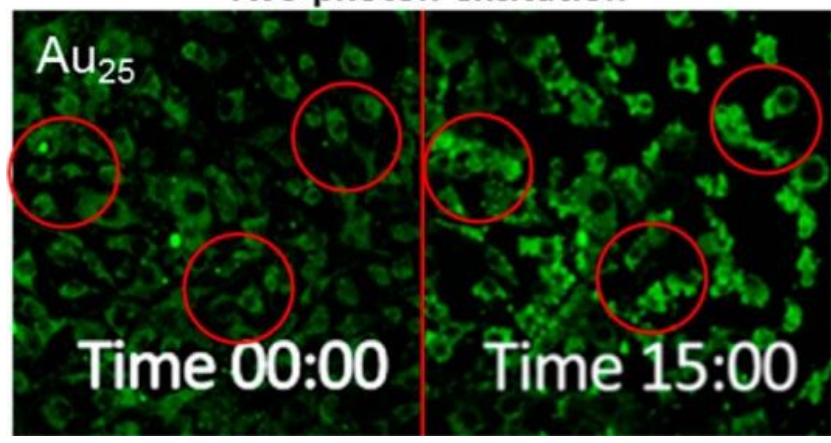

Figure 6: Comparison of one- (top panel) and two-photon (middle and bottom panels) excited fluorescence microscopy images of NIH/3T3 mouse fibroblast cells with $400 \mathrm{mg} / \mathrm{mLAu} 25(\mathrm{GSH})_{18}\left(\mathrm{Au}_{25} \mathrm{NCs}\right)$. The increase in fluorescence intensity is due to $\mathrm{NADH}$, converted from NAD+.(Top panel) Under one-photon excitation (400 nm) with $\mathrm{Au}_{25} \mathrm{NCs}$, the energy was not sufficient to trigger PDT within a 20 min time frame, as evidenced by the integrity of the cell after $18 \mathrm{~min}$. (middle panel) Under two-photon excitation $\left(800 \mathrm{~nm}\right.$ ) without $\mathrm{Au}_{25}$ nanoclusters, the control experiment shows that the cells remain intact after excitation in the absence of the nanoclusters. (bottom panel) Under two-photon excitation $(800 \mathrm{~nm})$ with $\mathrm{Au}_{25} \mathrm{NCs}$. This experiment confirms that cell death is triggered by photodynamic therapy with the nanoclusters (see the deformation and, ultimately, shrinkage of the cells indicating membrane rupture and release of cell contents in to the surrounding). This figure has been reproduced from ref. 110 with permission from American Chemical Society. 
with heterometals; 3) exploiting aggregation-induced emission; 4) self-assembling nanocluster units into cluster-based networks. These strategies could be "translated" to the nonlinear optical regime (2-photon excited fluorescence for instance) useful for multi-photon excitation microscopy.

Currently, using gold or silver nanoclusters for multiphoton imaging is still a challenging issue as their luminescence quantum yields are relatively small. There are also several twophoton absorption applications other than two-photon bioimaging, such as optical data storage, ${ }^{106}$ and optical limiting, 94,107 where gold and silver nanoclusters might be useful.

The drawback of "floppy" ligands, leading to moderate quantum yields, can become a serious advantage for therapeutic purposes. Indeed, Large TPA means that the clusters are efficient light absorbers. The absorbed photon energy (light) can be converted into strong localized heat, which may ultimately destroy cancer cells via hyperthermia. This process, called 2-Photon thermal therapy $(2 \mathrm{PTT})^{108}$ - is somewhat similar to plasmonic photothermal therapy (PPTT), ${ }^{109}$ using linear absorption of nanoparticles. It may be interesting to compare the efficiency of both processes to evaluate the added value of using NLO and ligated gold or silver NCs. On the other hand, photodynamic therapy (PDT) is a noninvasive medical treatment technique for many diseases. Upon activating drug molecules or nanoparticles by absorbing light of a particular wavelength (both by one- or two-photon processes), excitation energy is eventually transferred to the nearby oxygen molecules after a series of photophysical processes in order to generate cytotoxic reactive oxygen species, mostly singlet oxygen, for cell apoptosis. Recently Goodson and co-workers ${ }^{110}$ investigated three different metal nanoclusters, $\mathrm{Au}_{25}, \mathrm{Ag}_{32}$, and $\mathrm{Au}_{144}$, for their ${ }^{1} \mathrm{O}_{2}$ generation efficiency. They showed that nanoclusters (in particular) present a ${ }^{1} \mathrm{O}_{2}$ generation rate that is several orders of magnitude higher than nanoparticles $(>5 \mathrm{~nm}$ ) due to a high absorption cross-section-to-volume ratio for nanoclusters. The effectiveness of PDT in live cells with nanoclusters was demonstrated by two-photon excitation compared to onephoton excitation for $\mathrm{Au}_{25}$ nanoclusters as shown in Fig. 6 . The implication of the above results points toward new efficient two-photon targets both for photothermal and photodynamic therapies.

Finally, metal nanoclusters have been extensively studied in solution for their distinctive optical properties. However, many applications of nanoclusters involve their use in the solid state like films. $\mathrm{Au}_{25} \mathrm{NCs}$ in polystyrene hosts was used as the model for studying the optical properties of nanocluster films. In particular, the formation of nanocluster films enormously reduces the cluster-cluster distances to a few nanometers, providing huge two-photon absorption cross sections. ${ }^{111}$ From a theoretical point of view, it is important to correct artefacts such as unrealistically large TPA values due to the resonance between one-photon and two-photon excitation as well as to avoid quantitative aspects which depend on calculation details. Nevertheless, the role played by theoretical contributions is crucial for the design of new "ligand-core NLOphores". There are several aspects for molecular-like ligated quantum clusters which have to be considered: (i) The ratio of a number of metallic atoms versus the number of ligands which is important for the formation of metallic cores with nonuniform electronic distribution in the context of nonlinear properties as well as inducing one-photon absorption on desired wavelengths important for the application. (ii) The introduction of hetero-atom (e.g. silver in ligated gold clusters) might be an important issue for the future which can be easily investigated theoretically. (iii) The role of ligands is also crucial for applications. For example, increasing the fluorescence quantum yield by increasing the rigidity of ligated nanoclusters by the proper choice of ligands can be predicted theoretically. In short, the theoretical approach is important for proposing concepts for building up new NLO-phores, by stimulating their experimental realization.

With in-depth research on the nonlinear optical characteristics of atomically precise nanoclusters, correlations between the structure and nonlinear properties will hopefully be elucidated and there should be more optical applications in particular in biological imaging and therapy.

\section{Conflicts of interest}

There are no conflicts to declare.

\section{Acknowledgments}

The studies discussed in this feature article are the result of the work of many talented group members and graduate students including, Franck Bertorelle, Clothilde Comby-Zerbino, Christophe Moulin, Željka Sanader, Martina Perić, Marjan Krstić, Philippe Dugourd, Driss Rayane, Isabelle Russier-Antoine and Pierre-François Brevet. Therefore, we wish to express our deepest gratitude to all of them. This research was partially supported by the project STIM - REI, Contract Number: KK.01.1.1.01.0003, funded by the European Union through the European Regional Development Fund - the Operational Programme Competitiveness and Cohesion 2014-2020 (KK.01.1.1.01). We would also like to acknowledge the financial support received from the French-Croatian project "International Laboratory for Nano Clusters and Biological Aging, LIA NCBA".

\section{References}

1. A. M. Smith, M. C. Mancini and S. Nie, Nature Nanotechnology, 2009, 4, 710.

2. E. Hemmer, A. Benayas, F. Légaré and F. Vetrone, Nanoscale Horizons, 2016, 1, 168-184.

3. Kenry, Y. Duan and B. Liu, Advanced Materials, 2018, 30, 1802394.

4. S. He, J. Song, J. Qu and Z. Cheng, Chemical Society Reviews, 2018, 47, 4258-4278.

5. Y. Cai, Z. Wei, C. Song, C. Tang, W. Han and X. Dong, Chemical Society Reviews, 2019, 48, 22-37. 

Chemistry B, 2018, 6, 349-365.

7. A. Haque, M. S. H. Faizi, J. A. Rather and M. S. Khan, Bioorganic \& Medicinal Chemistry, 2017, 25, 2017-2034.

8. J. Pan, F. Li and J. H. Choi, Journal of Materials Chemistry $B$, 2017, 5, 6511-6522.

9. J. Mal, Y. V. Nancharaiah, E. D. van Hullebusch and P. N. L. Lens, RSC Advances, 2016, 6, 41477-41495.

10. B. A. Kairdolf, A. M. Smith, T. H. Stokes, M. D. Wang, A. N. Young and S. Nie, Annual Review of Analytical Chemistry, 2013, 6, 143-162.

11. I. V. Martynenko, A. P. Litvin, F. Purcell-Milton, A. V. Baranov, A. V. Fedorov and Y. K. Gun'ko, Journal of Materials Chemistry B, 2017, 5, 6701-6727.

12. H. Dong, S.-R. Du, X.-Y. Zheng, G.-M. Lyu, L.-D. Sun, L.-D. Li, P.-Z. Zhang, C. Zhang and C.-H. Yan, Chemical Reviews, 2015, 115, 10725-10815.

13. Z. Guo, S. Park, J. Yoon and I. Shin, Chemical Society Reviews, 2014, 43, 16-29.

14. X. Yuan, Z. Luo, Y. Yu, Q. Yao and J. Xie, Chemistry - An Asian Journal, 2013, 8, 858-871.

15. R. Jin, C. Zeng, M. Zhou and Y. Chen, Chemical Reviews, 2016, 116, 10346-10413.

16. I. Chakraborty and T. Pradeep, Chemical Reviews, 2017, 117, 8208-8271.

17. R. Jin, Nanoscale, 2010, 2, 343-362.

18. R. Jin, Nanoscale, 2015, 7, 1549-1565.

19. J. Zheng, C. Zhang and R. M. Dickson, Phys. Rev. Lett., 2004, 93, 077402/077401-077402/077404.

20. H. Duan and S. Nie, J. Am. Chem. Soc., 2007, 129, 24122413.

21. C.-A. J. Lin, T.-Y. Yang, C.-H. Lee, S. H. Huang, R. A. Sperling, M. Zanella, J. K. Li, J.-L. Shen, H.-H. Wang, H.-I. Yeh, W. J. Parak and W. H. Chang, ACS Nano, 2009, 3, 395-401. M. A. H. Muhammed, P. K. Verma, S. K. Pal, R. C. A. Kumar, S. Paul, R. V. Omkumar and T. Pradeep, Chem. - Eur. J., 2009, 15, 10110-10120, S10110/10111-S10110/10119. Z. Wang, W. Cai and J. Sui, ChemPhysChem, 2009, 10, 20122015.

H. Kawasaki, K. Hamaguchi, I. Osaka and R. Arakawa, Adv. Funct. Mater., 2011, 21, 3508-3515.

25. L. Shang, N. Azadfar, F. Stockmar, W. Send, V. Trouillet, M. Bruns, D. Gerthsen and G. U. Nienhaus, Small, 2011, 7, 2614-2620.

26. X. Yuan, Z. Luuuo, Q. Zhang, X. Zhang, Y. Zheng, J. Y. Lee and J. Xie, ACS Nano, 2011, 5, 8800-8808.

27. T. A. C. Kennedy, J. L. MacLean and J. Liu, Chem. Commun. (Cambridge, U. K.), 2012, 48, 6845-6847.

28. X. Wen, P. Yu, Y.-R. Toh, A.-C. Hsu, Y.-C. Lee and J. Tang, J. Phys. Chem. C, 2012, 116, 19032-19038.

29. L. Yan, Y. Cai, B. Zheng, H. Yuan, Y. Guo, D. Xiao and M. M. F. Choi, J. Mater. Chem., 2012, 22, 1000-1005.

30. F. Aldeek, M. A. H. Muhammed, G. Palui, N. Zhan and H. Mattoussi, ACS Nano, 2013, 7, 2509-2521.

31.

36. J. Sun and Y. Jin, J. Mater. Chem. C, 2014, 2, 8000-8011. L. Zhang and E. Wang, Nano Today, 2014, 9, 132-157. L.-Y. Chen, C.-W. Wang, Z. Yuan and H.-T. Chang, Anal. Chem. (Washington, DC, U. S.), 2015, 87, 216-229. L.-Y. Chen, C.-W. Wang, Z. Yuan and H.-T. Chang, Analytical Chemistry, 2015, 87, 216-229.
35.

40.

Z. Luo, K. Zheng and J. Xie, Chemical Communications, 2014, 50, 5143-5155.

L. Shang and G. U. Nienhaus, Biophysical Reviews, 2012, 4, 313-322.

Y. Chen, D. M. Montana, H. Wei, J. M. Cordero, M. Schneider, X. Le Guével, O. Chen, O. T. Bruns and M. G. Bawendi, Nano Letters, 2017, 17, 6330-6334.

D. Shen, M. Henry, V. Trouillet, C. Comby-Zerbino, F. Bertorelle, L. Sancey, R. Antoine, J.-L. Coll, V. Josserand and X. L. Guével, APL Materials, 2017, 5, 053404.

R. W. Boyd, Nonlinear Optics, Academic Press, Boston, Second Edition, 2003; and Third Edition 2008 edn., 1992. H. M. Kim and B. R. Cho, Chemical Reviews, 2015, 115, 5014-5055.

H.-W. Liu, Y. Liu, P. Wang and X.-B. Zhang, Methods and Applications in Fluorescence, 2017, 5, 012003.

F. Terenziani, C. Katan, E. Badaeva, S. Tretiak and M. Blanchard-Desce, Advanced Materials, 2008, 20, 46414678.

N. G. Horton, K. Wang, D. Kobat, C. G. Clark, F. W. Wise, C. B. Schaffer and C. Xu, Nature Photonics, 2013, 7, 205.

C. Xu, W. Zipfel, J. B. Shear, R. M. Williams and W. W. Webb, Proceedings of the National Academy of Sciences, 1996, 93, 10763-10768.

M. Pawlicki, H. A. Collins, R. G. Denning and H. L. Anderson, Angewandte Chemie International Edition, 2009, 48, 32443266.

Q. Zhang, X. Tian, H. Zhou, J. Wu and Y. Tian, Materials, 2017, 10, 223.

N. S. Makarov, P. C. Lau, C. Olson, K. A. Velizhanin, K. M. Solntsev, K. Kieu, S. Kilina, S. Tretiak, R. A. Norwood, N. Peyghambarian and J. W. Perry, ACS Nano, 2014, 8, 1257212586.

T.-M. Liu, J. Conde, T. Lipiński, A. Bednarkiewicz and C.-C. Huang, Npg Asia Materials, 2016, 8, e295.

G. Ramakrishna, O. Varnavski, J. Kim, D. Lee and T. Goodson, J. Am. Chem. Soc., 2008, 130, 5032-5033.

S. A. Patel, C. I. Richards, J.-C. Hsiang and R. M. Dickson, J. Am. Chem. Soc., 2008, 130, 11602-11603.

R. Antoine, Frontier Research Today, 2018, 1, 01001.

R. Antoine, in Molecular Spectroscopy-Experiment and Theory: From Molecules to Functional Materials, eds. A. Koleżyński and M. Król, Springer International Publishing, Cham, 2019, DOI: 10.1007/978-3-030-01355-4_5, pp. 139160.

53. R. Antoine and V. Bonacic-Koutecky, Liganded silver and gold quantum clusters. Towards a new class of nonlinear optical nanomaterials, Springer, Cham, 2018.

54. I. Russier-Antoine, F. Bertorelle, N. Calin, Z. Sanader, M. Krstic, C. Comby-Zerbino, P. Dugourd, P.-F. Brevet, V. Bonacic-Koutecky and R. Antoine, Nanoscale, 2017, 9, 1221-1228.

55. Z. Sanader, M. Krstic, I. Russier-Antoine, F. Bertorelle, P. Dugourd, P.-F. Brevet, R. Antoine and V. Bonacic-Koutecky, Phys. Chem. Chem. Phys., 2016, 18, 12404-12408.

56. A. P. Demchenko and Editor, Advanced Fluorescence Reporters In Chemistry And Biology I, Fundamentals And Molecular Design. [In: Springer Ser. Fluoresc., 2010; 8], Springer $\mathrm{GmbH}, 2010$. 

294.

58. L. Frediani, Z. Rinkevicius and H. Ågren, The Journal of Chemical Physics, 2005, 122, 244104.

59. P. Norman and K. Ruud, in Non-Linear Optical Properties of Matter: From Molecules to Condensed Phases, eds. M. G. Papadopoulos, A. J. Sadlej and J. Leszczynski, Springer Netherlands, Dordrecht, 2006, DOI: 10.1007/1-4020-48505_1, pp. 1-49.

Dalton, Journal, A Molecular Electronic Structure Program Release Dalton 2016. (2015. Available at https://daltonprogram.org).

61. K. Aidas, C. Angeli, K. L. Bak, V. Bakken, R. Bast, L. Boman, O. Christiansen, R. Cimiraglia, S. Coriani, P. Dahle, E. K. Dalskov, U. Ekström, T. Enevoldsen, J. J. Eriksen, P. Ettenhuber, B. Fernández, L. Ferrighi, H. Fliegl, L. Frediani, K. Hald, A. Halkier, C. Hättig, H. Heiberg, T. Helgaker, A. C. Hennum, H. Hettema, E. Hjertenæs, S. Høst, I.-M. Høyvik, M. F. Iozzi, B. Jansík, H. J. A. Jensen, D. Jonsson, P. Jørgensen, J. Kauczor, S. Kirpekar, T. Kjærgaard, W. Klopper, S. Knecht, R. Kobayashi, H. Koch, J. Kongsted, A. Krapp, K. Kristensen, A. Ligabue, O. B. Lutnæs, J. I. Melo, K. V. Mikkelsen, R. H. Myhre, C. Neiss, C. B. Nielsen, P. Norman, J. Olsen, J. M. H. Olsen, A. Osted, M. J. Packer, F. Pawlowski, T. B. Pedersen, P. F. Provasi, S. Reine, Z. Rinkevicius, T. A. Ruden, K. Ruud, V. V. Rybkin, P. Sałek, C. C. M. Samson, A. S. de Merás, T. Saue, S. P. A. Sauer, B. Schimmelpfennig, K. Sneskov, A. H. Steindal, K. O. Sylvester-Hvid, P. R. Taylor, A. M. Teale, E. I. Tellgren, D. P. Tew, A. J. Thorvaldsen, L. Thøgersen, O. Vahtras, M. A. Watson, D. J. D. Wilson, M. Ziolkowski and H. Ågren, Wiley Interdisciplinary Reviews: Computational Molecular Science, 2014, 4, 269-284.

62. P. N. Day, K. A. Nguyen and R. Pachter, J. Chem. Theory Comput., 2010, 6, 2809-2821.

63. P. N. Day, R. Pachter, K. A. Nguyen and T. P. Bigioni, Journal of Physical Chemistry A, 2016, 120, 507-518.

64. P. N. Day, R. Pachter and K. A. Nguyen, Journal of Physical Chemistry A, 2017, 121, 326-333.

65. K. A. Nguyen, R. Pachter and P. N. Day, The Journal of Physical Chemistry A, 2017, 121, 1748-1759.

66. Z. Hu and L. Jensen, Chem. Sci., 2017, 8, 4595-4601.

67. M. Sheik-Bahae, A. A. Said, T. H. Wei, D. J. Hagan and E. W. V. Stryland, IEEE Journal of Quantum Electronics, 1990, 26, 760-769.

68. A. S. Reyna, I. Russier-Antoine, F. Bertorelle, E. Benichou, P. Dugourd, R. Antoine, P.-F. Brevet and C. B. de Araújo, The Journal of Physical Chemistry C, 2018, 122, 1868218689.

69. J. Olesiak-Banska, M. Waszkielewicz, K. Matczyszyn and M. Samoc, RSC Advances, 2016, 6, 98748-98752.

70. J.-M. Lamarre, F. Billard, C. H. Kerboua, M. Lequime, S. Roorda and L. Martinu, Optics Communications, 2008, 281, 331-340.

71. F. Bertorelle, C. Moulin, A. Soleilhac, C. Comby-Zerbino, P. Dugourd, I. Russier-Antoine, P.-F. Brevet and R. Antoine, ChemPhysChem, 2018, 19, 165-168.

72. F. Bertorelle, I. Russier-Antoine, N. Calin, C. CombyZerbino, A. Bensalah-Ledoux, S. Guy, P. Dugourd, P.-F. Brevet, Z. Sanader, M. Krstic, V. Bonacic-Koutecky and R. Antoine, J. Phys. Chem. Lett., 2017, 8, 1979-1985.

73. F. Bertorelle, I. Russier-Antoine, C. Comby-Zerbino, F. Chirot, P. Dugourd, P.-F. Brevet and R. Antoine, ACS Omega, 2018, 3, 15635-15642.
74.
I. Russier-Antoine, F. Bertorelle, R. Hamouda, D. Rayane, P. Dugourd, P.-F. Brevet, R. Antoine, Z. Sanader and V. Bonacic-Koutecky, Nanoscale, 2016, 8, 2892-2898.

I. Russier-Antoine, F. Bertorelle, M. Vojkovic, D. Rayane, E. Salmon, C. Jonin, P. Dugourd, R. Antoine and P.-F. Brevet, Nanoscale, 2014, 6, 13572-13578.

W. Kaiser and C. G. B. Garrett, Physical Review Letters, 1961, 7, 229-231.

C. Xu and W. W. Webb, J. Opt. Soc. Am. B, 1996, 13, 481491.

H. A. Kindi, A. Mohamed, S. Kajimoto, N. Zhanpeisov, H. Horino, Y. Shibata, I. I. Rzeznicka and H. Fukumura, Journal of Photochemistry and Photobiology A: Chemistry, 2018, 357, 168-174.

S. H. Yau, O. Varnavski and T. Goodson, III, Acc. Chem. Res., 2013, 46, 1506-1516.

F. Bertorelle, R. Hamouda, D. Rayane, M. Broyer, R. Antoine, P. Dugourd, L. Gell, A. Kulesza, R. Mitric and V. Bonacic-Koutecky, Nanoscale, 2013, 5, 5637-5643.

V. Bonacic-Koutecky, A. Kulesza, L. Gell, R. Mitric, R. Antoine, F. Bertorelle, R. Hamouda, D. Rayane, M. Broyer, T. Tabarin and P. Dugourd, Physical Chemistry Chemical Physics, 2012, 14, 9282-9290.

V. Bonačić-Koutecký, Advances in Physics: X, 2017, 2, 695716.

D. R. Kauffman, D. Alfonso, C. Matranga, P. Ohodnicki, X. Deng, R. C. Siva, C. Zeng and R. Jin, Chemical Science, 2014, 5, 3151-3157.

M. Zhu, W. T. Eckenhoff, T. Pintauer and R. Jin, The Journal of Physical Chemistry C, 2008, 112, 14221-14224.

I. Chakraborty, J. Erusappan, A. Govindarajan, K. S. Sugi, T. Udayabhaskararao, A. Ghosh and T. Pradeep, Nanoscale, 2014, 6, 8024-8031.

S. Knoppe and T. Verbiest, Journal of the American Chemical Society, 2017, 139, 14853-14856.

P. Galletto, P.-F. Brevet, H. H. Girault, R. Antoine and M. Broyer, Chemical Communications, 1999, 7, 581.

R. Antoine, M. Pellarin, B. Palpant, M. Broyer, B. Prével, P. Galletto, P.-F. Brevet and H. H. Girault, Journal of Applied Physics, 1998, 84, 4532-4536.

R. Antoine, P.-F. Brevet, H. H. Girault, D. Bethell and D. J. Schiffrin, Chemical Communications, 1997, 19, 1901-1902. H. Al Kindi, A. Mohamed, S. Kajimoto, N. Zhanpeisov, H. Horino, Y. Shibata, I. I. Rzeznicka and H. Fukumura, J. Photochem. Photobiol., A, 2018, 357, 168-174.

Y. Hamanaka, N. Okada, K. Fukagawa, A. Nakamura, Y. Tai and J. Murakami, J. Phys. Chem. C, 2012, 116, 1076010765.

E. Oh, F. K. Fatemi, M. Currie, J. B. Delehanty, T. Pons, A Fragola, S. Leveque-Fort, R. Goswami, K. Susumu, A. L. Huston and I. L. Medintz, Part. Part. Syst. Charact., 2013, 30, 453-466.

J. Olesiak-Banska, M. Waszkielewicz, K. Matczyszyn and M. Samoc, RSC Adv., 2016, 6, 98748-98752.

R. Philip, P. Chantharasupawong, H. Qian, R. Jin and J. Thomas, Nano Lett., 2012, 12, 4661-4667.

L. Polavarapu, M. Manna and Q.-H. Xu, Nanoscale, 2011, 3, 429-434.

C.-L. Liu, M.-L. Ho, Y.-C. Chen, C.-C. Hsieh, Y.-C. Lin, Y.-H. Wang, M.-J. Yang, H.-S. Duan, B.-S. Chen, J.-F. Lee, J.-K. Hsiao and P.-T. Chou, The Journal of Physical Chemistry C, 2009, 113, 21082-21089.

M. Kasha, Discussions of the Faraday Society, 1950, 9, 1419. 
98. N. J. R. Turro, V.; Scaiano, J. C., Modern Molecular Photochemistry of Organic Molecules., University Science Books: Sausalito, CA, 2010.

99. L. Shang, R. M. Doerlich, S. Brandholt, R. Schneider, V. Trouillet, M. Bruns, D. Gerthsen and G. U. Nienhaus, Nanoscale, 2011, 3, 2009-2014.

100. R. Khandelia, S. Bhandari, U. N. Pan, S. S. Ghosh and A. Chattopadhyay, Small, 2015, 11, 4075-4081.

101. U. N. Pan, R. Khandelia, P. Sanpui, S. Das, A. Paul and A. Chattopadhyay, ACS Appl. Mater. Interfaces, 2017, 9, 19495-19501.

102. C.-L. Liu, H.-T. Wu, Y.-H. Hsiao, C.-W. Lai, C.-W. Shih, Y.-K. Peng, K.-C. Tang, H.-W. Chang, Y.-C. Chien, J.-K. Hsiao, J.-T. Cheng and P.-T. Chou, Angew. Chem., Int. Ed., 2011, 50, 7056-7060, s7056/7051-S7056/7058.

103. Z. Wu and R. Jin, Nano Letters, 2010, 10, 2568-2573.

104. K. Pyo, V. D. Thanthirige, K. Kwak, P. Pandurangan, G. Ramakrishna and D. Lee, Journal of the American Chemical Society, 2015, 137, 8244-8250.

105. X. Kang and M. Zhu, Chem. Soc. Rev., 2019, (in press).

106. J. Lott, C. Ryan, B. Valle, J. R. Johnson III, D. A. Schiraldi, J. Shan, K. D. Singer and C. Weder, Advanced Materials, 2011, 23, 2425-2429.

107. A. S. Reyna, I. Russier-Antoine, F. Bertorelle, E. Benichou, P. Dugourd, R. Antoine, P.-F. Brevet and C. B. de Araujo, J. Phys. Chem. C, 2018, 122, 18682-18689.

108. L. M. A. Ali, E. Mathlouthi, M. Kajdan, M. Daurat, J. Long, R. Sidi-Boulenouar, M. Cardoso, C. Goze-Bac, N. Amdouni, Y. Guari, J. Larionova and M. Gary-Bobo, Photodiagnosis and Photodynamic Therapy, 2018, 22, 65-69.

109. X. Huang and M. A. El-Sayed, Alexandria Journal of Medicine, 2011, 47, 1-9.

110. R. Ho-Wu, S. H. Yau and T. Goodson, The Journal of Physical Chemistry B, 2017, 121, 10073-10080.

111. R. Ho-Wu, S. H. Yau and T. Goodson, III, ACS Nano, 2016, 10, 562-572. 